\title{
ANÁLISE DE CRESCIMENTO DO CAPIM-ELEFANTE 'NAPIER’ ADUBADO E IRRIGADO ${ }^{1}$
}

\author{
Growth analysis of 'Napier’ elephant grass fertilized and irrigated \\ Alex Carvalho Andrade², Dilermando Miranda da Fonseca ${ }^{3}$, Rogério dos Santos Lopes ${ }^{4}$, \\ Domício do Nascimento Júnior ${ }^{3}$, Paulo Roberto Cecon ${ }^{5}$, Domingos Sávio Queiroz ${ }^{6}$, \\ Dalton Henrique Pereira ${ }^{7}$, Sidnei Tavares Reis ${ }^{8}$
}

\begin{abstract}
RESUMO
Avaliaram-se os índices de crescimento taxa de crescimento relativo (TCR), taxa assimilatória líquida (TAL), razão de área foliar (RAF), índice de área foliar (IAF) e a interceptação luminosa do capim-elefante 'Napier' após pastejo. O trabalho consistiu de dois experimentos, com quatro tratamentos de adubação de N e K, em kg/ha (T1: $100 \mathrm{~kg}$ de N e 80 kg de K, T2: 200 kg de N e $160 \mathrm{~kg}$ de K, T3: $300 \mathrm{~kg}$ de N e $240 \mathrm{~kg}$ de K e T4: $400 \mathrm{~kg}$ de N e $320 \mathrm{~kg}$ de K), sendo um irrigado e outro sem irrigação, segundo o delineamento de blocos ao acaso com três repetições. A análise estatística observou um esquema de parcela subdividida, tendo nas parcelas as doses de $\mathrm{N}$ e K e nas sub-parcelas as idades de rebrotação após pastejo (2, 8, 15, 45 e 123 dias), para IAF e interceptação de luz. O IAF na área irrigada aumentou de 0,28 para 8,27, média dos quatro tratamentos de $\mathrm{N}$ e K, entre a menor e maior idade de rebrotação. Na área não irrigada, também ocorreu um aumento no IAF, embora de menor magnitude que na área irrigada, de 0,16 para 7,76. Os valores médios de TCR, TAL e RAF foram 0,0083 g/g.dia, 3,57 g/ $\mathrm{cm}^{2}$. dia e $0,0021 \mathrm{~m}^{2} / \mathrm{g}, \mathrm{respec}-$ tivamente. A interceptação de luz aumentou com o aumento do IAF, estabilizando-se no 51,50 dia. Já a penetração de luz no interior do dossel diminuiu assintoticamente em função do IAF. O coeficiente de extinção variou de 0,29 na maior combinação de $\mathrm{N}$ e K, para 0,53 nas doses de $200 \mathrm{~kg} / \mathrm{ha}$ de $\mathrm{N}$ e $160 \mathrm{~kg} / \mathrm{ha}$ de $\mathrm{K}$.
\end{abstract}

Termos para indexação: coeficiente de extinção, índice de área foliar, interceptação luminosa, Pennisetum purpureum, taxa assimilatória líquida, taxa de crescimento relativo, razão de área foliar.

\begin{abstract}
The growth indexes were evaluated: relative to growth rate (RGR), net assimilation rate (NAR), leaf area ratio (LAR), leaf area index (LAI) and the luminous interception of the 'Napier' elephant grass after graze. The work consisted of two experiments for the study of four manuring treatments of $\mathrm{N}$ and $\mathrm{K}$, in $\mathrm{kg} / \mathrm{ha}$ (T1: $100 \mathrm{~kg}$ of $\mathrm{N}$ and $80 \mathrm{~kg}$ of $\mathrm{K}, \mathrm{T} 2: 200 \mathrm{~kg}$ of $\mathrm{N}$ and $160 \mathrm{~kg}$ of K, T3: $300 \mathrm{~kg}$ of $\mathrm{N}$ and $240 \mathrm{~kg}$ of $\mathrm{K}$ and T4: $400 \mathrm{~kg}$ of $\mathrm{N}$ and $320 \mathrm{~kg}$ of $\mathrm{K}$ ), being an irrigated and other without irrigation, according to the randomized block desing, with three replicates. The statistical analysis was donne in outline of split plot, tends in the portions the doses of $\mathrm{N}$ and $\mathrm{K}$, and in the sub-portions the regrowth ages after graze (2, 8, 15, 45 and 123 days) for LAI and interception of light. The LAI in the irrigated area increased from 0.28 to 8.27, average of the four treatments of $\mathrm{N}$ and $\mathrm{K}$, between the smaller and larger regrowth ages. In the not irrigated area also was verified an increase in LAI, although in smaller magnitude that in the irrigated area, of 0.16 for 7.76. The medium values of RGR, NAR and LAR were 0.0083 g/g.day, $3.57 \mathrm{~g} / \mathrm{cm}^{2}$.day and $0.0021 \mathrm{~m}^{2} / \mathrm{g}$, respectively. The light interception increased with the increase of the LAI, stabilizing in the 51.5th day. therefore, the light penetration inside the dossel reduced asymptotically in function of LAI. The extinction coefficient varied of 0.29 in the largest combination of $\mathrm{N}$ and $\mathrm{K}$ for 0.53 in the doses of $200 \mathrm{~kg} / \mathrm{ha}$ of $\mathrm{N}$ and $160 \mathrm{~kg} / \mathrm{ha}$ of $\mathrm{K}$.
\end{abstract}

Index terms: Extinction coeficient, interception of light, net assimilation rate, leaf area index, leaf area ratio, Pennisetum purpureum, relative growth rate.

(Recebido para publicação em 24 de setembro de 2003 e aprovado em 3 de novembro de 2004)

\section{INTRODUÇÃO}

As plantas diferem grandemente na sua produção de matéria seca (MS). Em solos férteis, com ótimo suprimento de água, a produção de biomassa é maior do que naqueles onde há escassez de nutrientes e/ou água, realçando a importância da adubação na produção forrageira. Além de água e nutrientes, diferentes condições de ambiente, como intensidade luminosa e temperatura, influenciam a produção das plantas forrageiras.

1. Parte da tese de Doutorado do primeiro autor, financiada pelo CNPq.

2. Zootecnista, Bolsista de Recém-Doutor da Universidade Federal de Lavras/UFLA - Caixa Postal 3037 - 37.200-000 - Lavras, MG - acandrade@ufla.br

3. Professor do Departamento de Zootecnia/DZO - Universidade Federal de Viçoas/UFV.

4. Zootecnista, D.Sc. forragicultura e pastagens.

5. Professor do DPI/Universidade Federal de Viçosa/UFV.

6. Pesquisador da EPAMIG, Viçosa-MG.

7. Zootecnista, estudante de Doutorado da UFV.

8. Eng. Agrônomo M.S.c. nutrição de ruminantes. 
A análise de crescimento possibilita identificar as características das plantas associadas às suas adaptações às condições de estresse, bem como seus potenciais de produção sob condições ótimas de crescimento. Também pode propiciar informações dos efeitos do ambiente sobre as diferenças entre espécies.

Segundo Radford (1967), as principais características de crescimento são as seguintes: taxa de crescimento da cultura (TCC); taxa de crescimento relativo (TCR); taxa assimilatória líquida (TAL); razão de área foliar (RAF), que se decompõe em área foliar específica (AFE) e razão de peso foliar (RPF); índice de área foliar (IAF) e duração da área foliar (D).

As características de crescimento variam em decorrência de alterações nos níveis de luz, temperatura, umidade e disponibilidade de nutrientes. Daí a necessidade do conhecimento das respostas morfológicas das espécies ao ambiente, para entendimento de adaptações das plantas às práticas de manejo a serem adotadas.

Entre todas as variáveis relacionadas ao crescimento e produção das plantas, a área foliar, interceptação de luz, fotossíntese e ambiente luminoso são muito importantes, visto que $90 \%$ do peso de MS das plantas são devidos à assimilação fotossintética de carbono (PEDREIRA et al., 1998). A importância dessas informações para o manejo da pastagem tem sido destacada por diferentes autores. Entretanto, muitos dos dados relacionados ao crescimento e ecofisiologia foram gerados em plantas de regiões temperadas, com pouca informação disponível para a maioria das espécies tropicais. Assim, objetivou-se com este estudo avaliar os aspectos de interceptação de luz, taxa de crescimento relativo, taxa assimilatória líquida e razão de área foliar do capim-elefante 'Napier' (Pennisetum purpureum Schum.), sob adubação e irrigação.

\section{MATERIAL E MÉTODOS}

As amostras de solo da área experimental revelaram as seguintes características químicas: $\mathrm{pH}\left(\mathrm{H}_{2} \mathrm{O}\right.$ 1:2,5) 5,3; P e K (Mehlich) 0,6 e $17 \mathrm{mg} / \mathrm{dm}^{3}$, respectivamente; $\mathrm{Ca}, \mathrm{Mg}$ e $\mathrm{Al}(\mathrm{KCl} 1 \mathrm{~mol} / \mathrm{L}), 1,8 ; 0,4$ e 0,2 $\mathrm{cmol}_{\mathrm{C}} / \mathrm{dm}^{3}$, respectivamente; $\mathrm{H}+\mathrm{Al}\left(\mathrm{Ca}(\mathrm{OAc})_{2} \quad 0,5\right.$ $\mathrm{mol} / \mathrm{L})$ 3,6 $\mathrm{cmol}_{\mathrm{c}} / \mathrm{dm}^{3}$. Em função dos resultados da análise de solo, foi efetuada a sua correção com base no método da saturação por bases (V\%) (CFSEMG, 1999), por meio da aplicação de calcário dolomítico, elevandose a saturação por bases a $70 \%$. Decorridos trinta dias após a aplicação do corretivo, foram abertos sulcos espaçados de $1 \mathrm{~m}$, onde foi aplicado o adubo fosfatado (200 kg/ha de $\mathrm{P}_{2} \mathrm{O}_{5}$ ).
Foram conduzidos dois experimentos simultâneos, para o estudo de adubações nitrogenada e potássica em capim-elefante. Os tratamentos consistiram da associação de quatro doses de nitrogênio (N) e potássio (K), em kg/ha (T1: $100 \mathrm{~kg}$ de $\mathrm{N}+80 \mathrm{~kg}$ de K, T2: $200 \mathrm{~kg}$ de $\mathrm{N}+160 \mathrm{~kg}$ de K, T3: $300 \mathrm{~kg}$ de N + $240 \mathrm{~kg}$ de K e T4: $400 \mathrm{~kg}$ de N + $320 \mathrm{~kg}$ de $\mathrm{K}$ ), sendo um experimento irrigado e outro sem irrigação, segundo o delineamento de blocos ao acaso com três repetições. Cada experimento constou de um total de 12 unidades experimentais (piquetes) de $300 \mathrm{~m}^{2}$, para acomodar as três repetições de cada tratamento. Todas as unidades experimentais foram submetidas a um pastejo de uniformização.

Durante o período de avaliação, a temperatura média máxima foi de $28,2^{\circ} \mathrm{C}$ e a mínima, de $8,3^{\circ} \mathrm{C}$. A precipitação pluvial total foi de $578,7 \mathrm{~mm}$ e a umidade relativa do ar variou entre 61,89 e 92,25\%.

As adubações nitrogenada e potássica foram parceladas em quatro aplicações na área irrigada, sendo $70 \%$ no período chuvoso e $30 \%$ no seco. Na área sem irrigação, esse parcelamento foi de três vezes, apenas no período chuvoso.

A irrigação foi realizada até meados de outubro, por meio de um sistema de aspersão convencional, observando turno de rega variável, usando-se o método do tanque classe A para estimativa da evapotranspiração de referência.

\section{Análise de crescimento}

Durante o período experimental (123 dias), estimaram-se os índices fisiológicos: taxa de crescimento relativo média $(\overline{T C R})$, taxa assimilatória líquida média $(\overline{T A L})$, razão de área foliar média ( $\overline{R A F})$ e índice de área foliar (IAF) do capim-elefante 'Napier'.

Para as estimativas dos índices fisiológicos, utilizaram-se as seguintes fórmulas descritas por Beadle (1993) e Radford (1967):

$$
\begin{aligned}
& \overline{T C R}=\frac{\ln W_{2}-\ln W_{1}}{t_{2}-t_{1}} ; \\
& \overline{T A L}=\frac{\left(W_{2}-W_{1}\right)\left(\ln S_{2}-\ln S_{1}\right)}{\left(S_{2}-S_{1}\right)\left(t_{2}-t_{1}\right)} ; \\
& \overline{R A F}=\frac{\left(S_{2}-S_{1}\right)\left(\ln W_{2}-\ln W_{1}\right)}{\left(W_{2}-W_{1}\right)\left(\ln S_{2}-\ln S_{1}\right)}
\end{aligned}
$$

em que $W_{1}, W_{2}$ e $S_{1}$ e $S_{2}$ são, respectivamente, os valores de peso de MS e área foliar da planta nos tempos $\mathrm{t}_{1} \mathrm{e}$ $\mathrm{t}_{2}$ (utilizou-se apenas o peso de MS da parte aérea).

Após a saída dos animais de cada piquete, foi retirada uma amostra de $1 \mathrm{~m}^{2}$ por piquete, rente ao solo, 
nas seguintes datas: 11/08/99, 16/08/99, 23/08/99, 22/09/99 e 09/12/99. A massa verde colhida em cada piquete foi colocada em lona e pesada no próprio local, em uma balança tipo dinamômetro, com divisões de 100 g. Após a pesagem, contou-se o número de perfilhos originados do solo, considerados como perfilhos basilares, e suas ramificações, como perfilhos aéreos. Em seguida, retiraram-se dessa amostra 10 plantas para determinação da área foliar.

As medições de área foliar foram realizadas no Departamento de Zootecnia da UFV, por intermédio de um medidor de área foliar portátil (LICOR 3000A). A amostra de 10 plantas teve suas lâminas foliares destacadas e passadas no aparelho medidor de área. A área foliar média de uma planta foi estimada dividindo-se o valor encontrado por 10. Em seguida, as lâminas foram acondicionadas em sacos de papel, pesadas e submetidas à secagem em estufa com ventilação forçada, a $65^{\circ} \mathrm{C}$, por 72 horas. A estimativa da área foliar total das plantas por $\mathrm{m}^{2}$ de solo foi obtida multiplicando-se o peso da MS de lâminas foliares, presente em $1 \mathrm{~m}^{2}$, pela área foliar de 10 plantas e dividindo-se o produto pelo peso de MS de lâminas foliares de 10 plantas.

\section{Interceptação de luz}

A intensidade luminosa foi medida por meio do aparelho "LINE QUANTUM SENSOR LI191SA" (linha de sensores quânticos) em três diferentes alturas acima do dossel, porção mediana e ao nível do solo - de uma touceira da vegetação previamente selecionada em cada piquete, nas seguintes idades de rebrotação: 12, 22, 44, 65 e 85 dias, das 11 às 13 h.

Durante esse período, estimaram-se a interceptação de luz (IL) no dossel (até o solo) e o coeficiente de extinção do capim-elefante. Para essas estimativas, utilizaram-se as seguintes fórmulas:

Interceptação de luz (IL), em porcentagem: $I L=100 \frac{\left(I_{0}-I\right)}{I_{0}}$, em que $\mathrm{I}_{0}=$ radiação (PAR) no topo do dossel e I=radiação (PAR) ao nível do solo.

Coeficiente de extinção (k): O coeficiente de extinção é dado pela equação: $L n_{\frac{I}{I_{0}}}=-k \times I A F$.

O $L n_{\frac{I}{I_{0}}}$ foi plotado contra o IAF e o k é dado pela declividade da curva.

Os valores de interceptação e penetração de luz e o coeficiente de extinção foram estimados apenas na área irrigada.

\section{Análise estatística}

Os valores dos índices de crescimento $\overline{T C R}$, $\overline{T A L}$ e $\overline{R A F}$ foram submetidos à análise de variância, separadamente, para as partes irrigada e não-irrigada. Foi feita uma relação entre os quadrados médios residuais dos dois experimentos (irrigado e não-irrigado). Quando o valor dessa relação era igual ou inferior a cinco, foi feita uma análise conjunta.

Os valores médios de IAF e intensidade luminosa, nas diferentes idades de corte, foram submetidos à análise de regressão, para descrever sua variação em função da idade da planta.

\section{RESULTADOS E DISCUSSÃO}

\section{Índice de área foliar (IAF)}

O desenvolvimento dos valores de IAF, na área irrigada, teve resposta sigmoidal sob todas as combinações de N e K, em função da idade de rebrotação (Figura 1). Na área não-irrigada, os valores de IAF apresentaram o mesmo comportamento. Entretanto, a recuperação da área foliar foi um pouco mais lenta, a partir do $54^{\circ}$ dia, coincidindo com o início das chuvas e também do aumento na temperatura.

A rápida recuperação da área foliar após o corte é influenciada pelas condições do ambiente, pelo IAF residual e pela idade média das folhas, visto que a capacidade fotossintética das folhas varia inversamente com a sua idade. Neste trabalho, o baixo IAF residual, com predominância de folhas mais velhas, combinado com condições desfavoráveis do meio ambiente como baixas temperaturas e baixa incidência luminosa, devido à época das avaliações (agosto a dezembro), condicionou lenta recuperação da área foliar nos primeiros dias de rebrotação.

$\mathrm{O}$ teste de médias, realizado dentro de cada idade de rebrotação, só apresentou diferença $(\mathrm{P}<0,05)$ aos 123 dias de crescimento, demonstrando superioridade no IAF referente à maior combinação de $\mathrm{N}$ e K em relação às demais (Tabela 1). Em razão da área foliar de uma planta ser proporcional ao número de seus perfilhos e à área foliar desses perfilhos, a maior densidade de perfilhos observada na maior combinação de $\mathrm{N}$ e $\mathrm{K}$, com certeza, foi o fator determinante dessa superioridade no IAF na maior dose de N e K. É importante realçar que o longo período entre as duas últimas avaliações (45 e 123 dias) pode ter mascarado uma possível diferença entre os tratamentos ao redor dos 50-60 dias de rebrotação. Esse fato é reforçado na Figura 1, na qual se observa que a partir do $55^{-}$dia as duas maiores combinações de $\mathrm{N}$ e K já apresentavam maiores valores de IAF. 


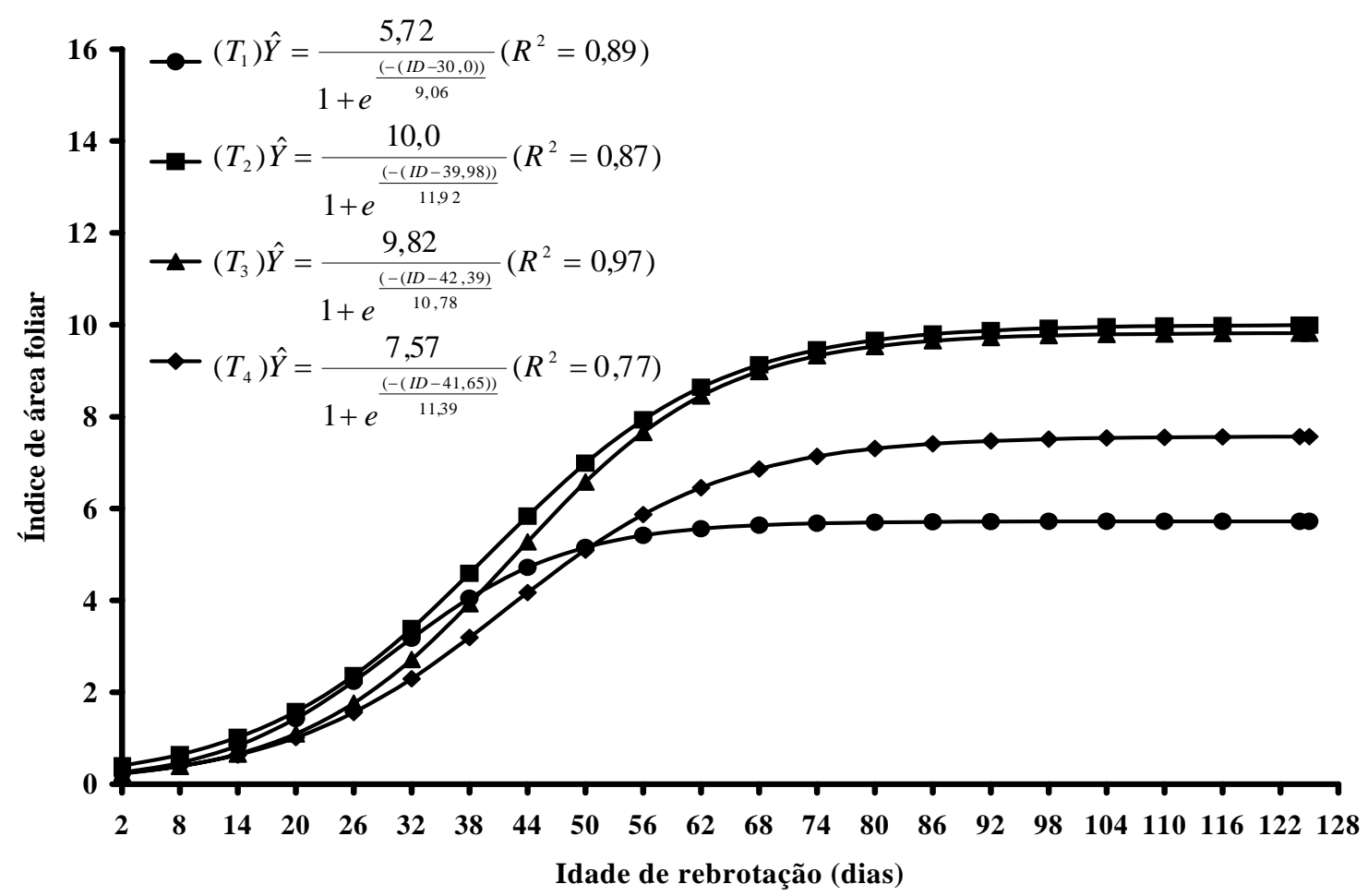

FIGURA 1 - Estimativa do índice de área foliar do capim-elefante irrigado, dentro de cada tratamento de $\mathrm{N}$ e $\mathrm{K}$, em função das diferentes idades de rebrotação (ID=dias).

TABELA 1 - Valores médios do índice de área foliar (IAF) do capim-elefante irrigado em diferentes idades.

\begin{tabular}{ccccccc}
\hline \multicolumn{2}{c}{ Tratamentos } & \multicolumn{5}{c}{ Idade de rebrotação (dias) } \\
\hline $\mathbf{N ~ ( k g / h a )}$ & $\mathbf{K ~ ( k g / h a )}$ & $\mathbf{2}$ & $\mathbf{8}$ & $\mathbf{1 5}$ & $\mathbf{4 5}$ & $\mathbf{1 2 3}$ \\
\hline 400 & 320 & $0,20 \mathrm{a}$ & $0,28 \mathrm{a}$ & $0,70 \mathrm{a}$ & $4,09 \mathrm{a}$ & $15,06 \mathrm{a}$ \\
300 & 240 & $0,14 \mathrm{a}$ & $0,25 \mathrm{a}$ & $0,85 \mathrm{a}$ & $5,49 \mathrm{a}$ & $9,82 \mathrm{~b}$ \\
200 & 160 & $0,12 \mathrm{a}$ & $0,54 \mathrm{a}$ & $0,64 \mathrm{a}$ & $4,33 \mathrm{a}$ & $7,56 \mathrm{bc}$ \\
100 & 80 & $0,06 \mathrm{a}$ & $0,40 \mathrm{a}$ & $0,73 \mathrm{a}$ & $4,46 \mathrm{a}$ & $6,05 \quad \mathrm{c}$ \\
\hline
\end{tabular}

$\mathrm{a}>\mathrm{b}>\mathrm{c}$ nas colunas (Teste de Tukey, $\mathrm{P}<0,05$ ).

Com relação à diferença entre os tratamentos dentro de cada idade de crescimento do capim-elefante 'Napier' não irrigado, à semelhança do observado na área irrigada, na área não irrigada apenas aos 123 dias de crescimento detectou-se diferença entre os tratamentos $(\mathrm{P}<0,05)$, registrando-se o menor valor de IAF na menor combinação de $\mathrm{N}$ e $\mathrm{K}$ em relação às maiores combinações desses nutrientes (Tabela 2). Com relação a essa diferença apenas aos 123 dias, o mesmo raciocínio desenvolvido para a área irrigada aplica-se à área sem irrigação. A inexistência de diferença entre as combinações até o $45^{\circ}$ dia provavelmente deve-se às baixas temperaturas e intensidade luminosa observadas neste período. 
Análise de crescimento do capim-elefante 'Napier’...

TABELA 2 - Valores médios do índice de área foliar (IAF) do capim-elefante na ausência de irrigação em diferentes idades de rebrotação.

\begin{tabular}{|c|c|c|c|c|c|c|}
\hline \multicolumn{2}{|c|}{ Tratamentos } & \multicolumn{5}{|c|}{ Idade de rebrotação (dias) } \\
\hline $\mathbf{N}$ & $\mathbf{K}$ & 2 & 8 & 15 & 45 & 123 \\
\hline \multicolumn{2}{|c|}{------ kg/ha ------ } & \multicolumn{5}{|c|}{ - } \\
\hline 300 & 240 & $0,18 \mathrm{a}$ & $0,21 \mathrm{a}$ & $0,65 \mathrm{a}$ & $1,64 \mathrm{a}$ & $11,03 a$ \\
\hline 400 & 320 & $0,32 \mathrm{a}$ & $0,26 \mathrm{a}$ & $0,49 \mathrm{a}$ & $1,43 a$ & $9,40 \mathrm{a}$ \\
\hline 200 & 160 & $0,50 \mathrm{a}$ & $0,28 a$ & $0,37 \mathrm{a}$ & $1,46 a$ & $8,92 \mathrm{a}$ \\
\hline 100 & 80 & $0,27 \mathrm{a}$ & $0,35 a$ & $0,26 a$ & 1,18a & $3,38 \mathrm{~b}$ \\
\hline
\end{tabular}

a $>$ b nas colunas (Teste de Tukey, $\mathrm{P}<0,05$ ).

\section{Interceptação de luz}

O padrão de variação da luminosidade, medida em diferentes posições do dossel (acima do dossel, porção mediana e ao nível do solo), em função das idades de rebrotação, não variou com as doses de N e K. A intensidade luminosa no topo do dossel cresceu linearmente com a idade de rebrotação, assim como a altura das plantas. Entretanto, a intensidade de luz na porção mediana e ao nível do solo decresceu linearmente com as idades de rebrotação (Figura 2).

O modelo sazonal de radiação obedece uma curva normal. No inverno, a intensidade luminosa é bem menor que no verão, devido às mudanças tanto na intensidade da radiação solar incidente quanto no comprimento do dia. $\mathrm{O}$ aumento verificado na intensidade luminosa incidente sobre o dossel, com o aumento na idade de rebrotação, reflete a variação estacional outono-primavera.

A interceptação de luz aumentou de maneira assintótica em função do IAF, independentemente das doses de N e K (Figura 3). Aumentos na interceptação de luz com o incremento do IAF foram observados em todas as combinações de $\mathrm{N}$ e $\mathrm{K}$, principalmente nos piquetes adubados com as maiores doses.

$\mathrm{O}$ aumento verificado na densidade de perfilhos contribuiu para o aumento do IAF (Figura 1) e, conseqüentemente, para maior interceptação de luz, principalmente nos piquetes adubados com as maiores doses (Figura 3).

A máxima intercepção de luz ocorreu aos 43, 53, 53 e 57 dias, da menor para a maior combinação de $\mathrm{N} \mathrm{e}$ $\mathrm{K}$, respectivamente, coincidindo com o intenso aumento da senescência (52 dias) e a estabilização do número de folhas vivas (51,5 dias). Esses fatos significam que, nas condições experimentais, o período de descanso do capim-elefante não deve ultrapassar 52 dias, ou 475 graus-dia (soma diária até 52 dias).

Graus-dia é o conceito de uma avaliação simplificada de energia à disposição de uma planta, em cada dia. Representa o acúmulo diário de energia que se situa acima da condição mínima e abaixo da condição máxima exigida pela planta. É importante ter em mente que o ciclo de vida da planta tem sua duração condicionada à energia do meio, sob condições ótimas dos demais fatores, isto é, a umidade, a disponibilidade de nutrientes no solo, etc. Dessa forma, no período experimental as plantas necessitaram de 52 dias de descanso, mas, com certeza, no período de verão, esse intervalo será menor em função de uma maior disponibilidade de luz e temperatura.

A quantidade de luz interceptada pelo dossel tem maior importância para a produção das forrageiras do que a quantidade de luz disponível. A interceptação de luz depende não somente do IAF da cultura, mas também de propriedades físicas das folhas e da estrutura do dossel, ou seja, o modo como as folhas estão dispostas (PARSONS et al., 1988). Fagundes et al. (1999) verificaram aumento na interceptação de luz e no coeficiente de extinção com o acréscimo da variação do IAF em pastagem de Tifton-85 mantida em diferentes alturas (50, 100, 150 e $200 \mathrm{~mm})$. Acrescentaram, ainda, que esse aumento na interceptação luminosa foi devido, em parte, a maiores e mais largas lâminas foliares nos relvados mantidos a maiores alturas. Essa mudança morfológica, associada a uma distribuição mais horizontal das folhas dentro do dossel, resultou em aumento nos valores de $\mathrm{k}$ com o aumento da altura da forrageira.

O coeficiente de extinção variou de 0,29 , nos piquetes de capim-elefante que receberam as maiores doses de $\mathrm{N}$ e $\mathrm{K}$, a 0,53 , referente às doses de $200 \mathrm{~kg} / \mathrm{ha}$ de $\mathrm{N}$ e $160 \mathrm{~kg} / \mathrm{ha}$ de K (Tabela 3). 


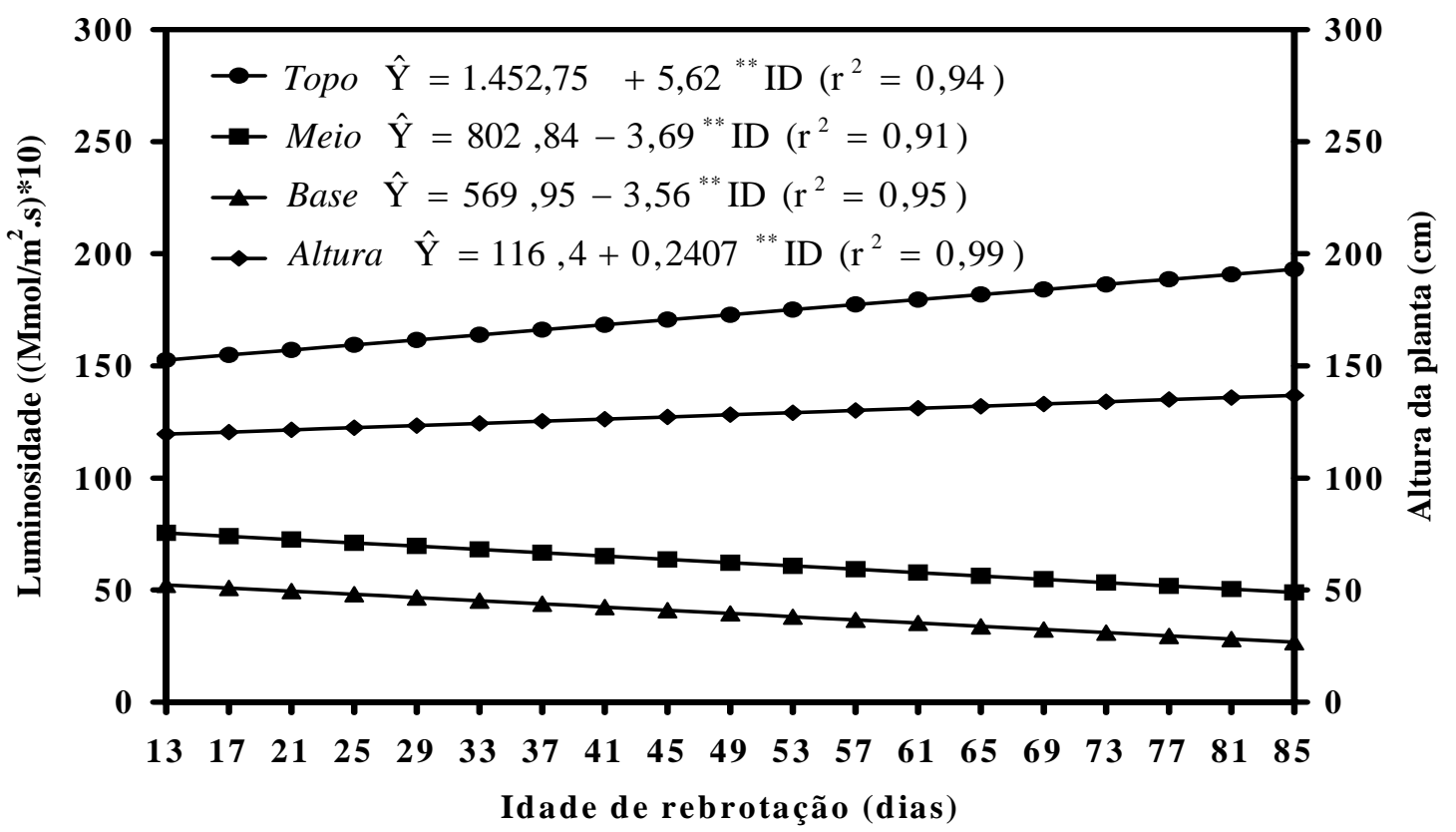

FIGURA 2 - Altura de plantas do capim-elefante 'Napier' sob as doses $100 \mathrm{~kg} / \mathrm{ha}$ de $\mathrm{N}$ e $80 \mathrm{~kg} / \mathrm{ha}$ de K em função da idade de rebrotação e intensidade luminosa incidente no topo, na altura média do dossel (meio) e ao nível do solo (base).

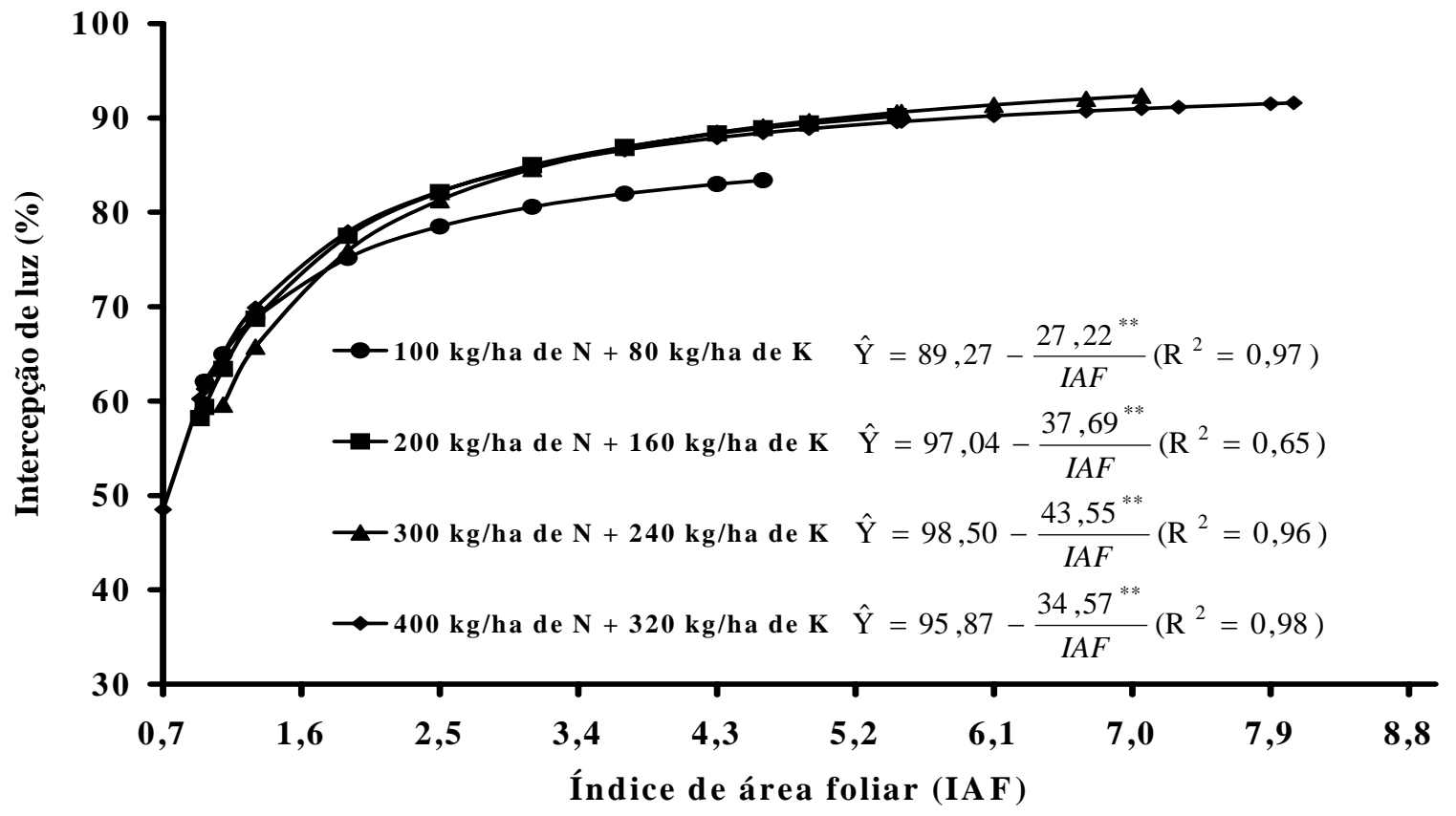

FIGURA 3 - Estimativa da interceptação de luz pelo capim-elefante irrigado em função do IAF, nas diferentes combinações de $\mathrm{N}$ e K. 
TABELA 3 - Coeficiente de extinção (k) estimado do capim-elefante nos diferentes tratamentos de N e K na presença de irrigação.

\begin{tabular}{ccc}
\hline \multicolumn{2}{c}{ Tratamento } & Coeficiente de extinção (k) \\
\hline $\mathbf{N}(\mathbf{k g} / \mathbf{h a})$ & $\mathbf{K ~ ( k g / h a )}$ & 0,29 \\
300 & 320 & 0,38 \\
200 & 240 & 0,53 \\
100 & 160 & 0,30 \\
\hline
\end{tabular}

Os valores de k obtidos, com exceção da combinação de $200 \mathrm{~kg} / \mathrm{ha}$ de $\mathrm{N}$ e $160 \mathrm{~kg} / \mathrm{ha}$ de $\mathrm{K}$, foram mais baixos que os relatados na literatura para gramíneas, que está entre 0,4 e 0,7 (ANSLOW, 1965; BROUGHAM, 1956, citados por BROWN \& BLASER, 1968). Entretanto, em culturas, a maneira como as folhas são arranjadas depende da densidade de plantio e da disposição das plantas na área (BERNARDES, 1987). A distribuição em grupamentos foliares dispersos deve implicar em menor coeficiente de extinção da luz no dossel (a depender do ângulo foliar e do ângulo de incidência da luz), significando que maior área foliar seria iluminada, distribuindo melhor a luz pela copa (LOOMIS \& WILLIAMS, 1969). Neste estudo, em função do pastejo e das características da espécie, formaram-se touceiras espaçadas uma das outras, em função do trânsito dos animais pelo piquete, contribuindo, dessa forma, para o menor valor de $\mathrm{k}$ obtido.

\section{Análise de crescimento}

Para nenhuma das três variáveis estudadas [taxa de crescimento relativo ( $\overline{T C R})$, taxa de assimilação líquida $(\overline{T A L})$ e razão de área foliar $(\overline{R A F})]$ foi observada significância dos efeitos de adubação, irrigação ou interação desses fatores, após análise conjunta dos dados das áreas irrigada e não irrigada. As médias dos efeitos dos tratamentos de N e K e irrigação encontram-se na Tabela 4.

Vários fatores podem influenciar os valores de TCR, como espécie ou variedade (GARNIER, 1992; LUDLOW \& WILSON, 1970), estádio de crescimento (EVANS, 1972; PINTO, 1993), além de variações nas condições climáticas (BENINCASA, 1988). Além disso, as diferenças relativas aos índices de crescimento também podem decorrer da forma como se obtêm esses valores. Tais valores, como os de TCR, estão abaixo do intervalo de 0,02 a 0,5 g/g.dia, relatados por Beadle (1993), para a maioria das espécies de plantas $C_{4}$, sob diversas condições de ambiente. Isso, provavelmente, foi devido à maneira como se calculou a TCR, ou seja, foi encontrado apenas um valor para todo o período experimental (123 dias). Sabe-se que a TCR apresenta valores mais altos nos primeiros dias de crescimento, reduzindo posteriormente. De fato, Gomide (1996), trabalhando com cinco cultivares do gênero Cynodon, registrou maiores valores de TCR nos períodos de 21 a 28 (0,084 g/g.dia) e 28 a 35 dias (0,026 g/g.dia).

No início do crescimento, a área foliar da planta é constituída de folhas jovens, com alta capacidade fotossintética, ou seja, alta eficiência de fixação do $\mathrm{CO}_{2}$ atmosférico. À medida que a planta se desenvolve, intensifica-se o processo de senescência foliar, reduzindo a eficiência fotossintética das folhas, além de aumentar as perdas respiratórias da planta, comprometendo a TAL e a RAF e, conseqüentemente, a TCR (WILSON, 1981).

Os maiores valores da TAL foram observados nas maiores combinações de $\mathrm{N}$ e K. Desses nutrientes, o $\mathrm{N}$ exerce um papel importante na TAL, pois é constituinte da molécula de clorofila, pigmento essencial à fotossíntese, e a TAL representa a diferença entre a produção de MS resultante da fotossíntese e a consumida pela respiração e fotorrespiração (praticamente inexistente em plantas C4).

Da mesma forma que a TCR, a TAL também se reduz com o aumento da idade da planta. Essa queda nos valores de TAL, com o avanço do desenvolvimento das plantas, provavelmente ocorre devido ao aumento da idade média das folhas, aliado ao autosombreamento das folhas inferiores da planta, reduzindo, assim, a sua eficiência fotossintética. Nesse sentido, Gomide et al. (1999) observaram queda na fotossíntese de folhas adultas de capim-mombaça de 42 para $17 \mathrm{mg}$ de $\mathrm{CO} 2 / \mathrm{dm} 2$.h entre as idades de $12 \mathrm{e}$ 16 dias. Gomide \& Gomide (1996) observaram redução na TAL das cultivares Vencedor e Mombaça de 40,2 e 20,0 g/m2.dia, aos 17 dias de idade, para 3,8 e $4,7 \mathrm{~g} / \mathrm{m} 2$.dia, aos 52 dias de crescimento, respectivamente. 
TABELA 4 - Valores médios da taxa de crescimento relativo média ( $\overline{T C R}$ ), taxa assimilatória líquida média ( $\overline{T A L})$ e razão de área foliar média ( $\overline{R A F}$ ) do capim-elefante nos diferentes tratamentos de $\mathrm{N}$ e $\mathrm{K}$, na presença e ausência de irrigação.

\begin{tabular}{|c|c|c|c|c|}
\hline \multicolumn{2}{|c|}{ Tratamentos } & \multicolumn{3}{|c|}{ Variáveis } \\
\hline $\mathbf{N}$ & $\mathbf{K}$ & $\overline{T C R}$ & $\overline{T A L}$ & $\overline{R A F}$ \\
\hline \multicolumn{2}{|c|}{------- kg/ha ------- } & ---- g/g.dia ---- & --- g/cm².dia --- & ---- m²/g ---- \\
\hline 400 & 320 & $0,0094 a$ & $4,04 a$ & $0,0021 \mathrm{a}$ \\
\hline 300 & 240 & $0,0087 a$ & 4,10a & $0,0021 \mathrm{a}$ \\
\hline 200 & 160 & 0,0096a & $3,42 \mathrm{a}$ & $0,0025 a$ \\
\hline 100 & 80 & 0,0056a & $2,74 a$ & $0,0018 \mathrm{a}$ \\
\hline \multicolumn{2}{|c|}{ Com irrigação } & 0,0092a & $3,68 \mathrm{a}$ & $0,0022 \mathrm{a}$ \\
\hline \multicolumn{2}{|c|}{ Sem irrigação } & $0,0075 a$ & $3,47 a$ & 0,0020a \\
\hline
\end{tabular}

a $>b$ nas colunas para adubação (Teste de Tukey, $\mathrm{P}<0,05$ ).

$a>b$ nas colunas para irrigação (Teste $F, P<0,05$ ).

No entanto, segundo Watson et al. (1966), a redução na TAL, com o avanço do desenvolvimento da planta, ocorre, principalmente, devido à redução na taxa fotossintética que ao aumento das perdas respiratórias das plantas. Entretanto, é importante ressaltar que a TAL não é determinada somente pela taxa fotossintética, mas também pela dimensão da área foliar, duração do período vegetativo, arquitetura da copa, translocação e partição de assimilados (BERNARDES, 1987).

Nas menores combinações de $\mathrm{N}$ e $\mathrm{K}$, o raciocínio é o inverso, ou seja, a menor disponibilidade de $\mathrm{N}$ pode ter afetado a fotossíntese, contribuindo para os menores valores de TAL obtidos. Outro fator que reforça essa possível menor taxa fotossintética é o maior valor do coeficiente de extinção (média das menores doses) (Tabela 3), pois maior $\mathrm{k}$ resulta de pior distribuição da radiação incidente e menor interceptação de luz (Figura 3), em função de menores valores de IAF (Figura 1).

Os baixos valores da RAF podem ser atribuídos à grande proporção de colmos e morte das folhas mais velhas, ou seja, menor valor de razão de peso foliar ao final do período de rebrotação. Normalmente, a RAF é reduzida com o avanço da idade devido às variações na relação fonte/dreno. Essa queda nos valores de RAF com a maturidade da planta está relacionada com variações na razão de peso foliar (RPF) e área foliar específica (AFE). Redução na RAF durante o desenvolvimento reflete maior alocação de assimilados para o desenvolvimento de colmos, raízes e partes reprodutivas, em detrimento da produção de folhas durante a fase linear de crescimento. De fato, Oliveira et al. (2000) observaram redução na RPF e na RAF em capim-bermuda “Tifton 85" (Cynodon spp.) com a idade de rebrotação, estimando-se valores entre 0,59 e $0,27 \mathrm{~g} / \mathrm{g}$, no período de 14 e 70 dias de rebrotação.

\section{CONCLUSÕES}

As adubações nitrogenada e potássica e a irrigação aumentaram os valores de IAF do capimelefante 'Napier'.

A absorção de luz aumentou com o aumento do IAF do capim-elefante 'Napier', estabilizando-se no $51,5^{\circ}$ dia.

O coeficiente de extinção médio do capimelefante 'Napier' foi de 0,37.

\section{REFERÊNCIAS BIBLIOGRÁFICAS}

BEADLE, C. L. Growth analysis. In: HALL, D. O.; BOLHARNORDENKAMPF, H. R.; LEEGOOD, R. C.; LONG, S. P. (Eds.). Photosynthesis and production in a changing environment: a field and laboratory manual. London: [s.n.], 1993. p. 36-46.

BENINCASA, M. M. P. Análise de crescimento de plantas: noções básicas. Jaboticabal: FUNEP, 1988. 41 p. 
BERNARDES, M. S. Fotossíntese no dossel das plantas cultivadas. In: CASTRO, P. R. S. et al. (Eds.). Ecofisiologia da produção agrícola. Piracicaba: Associação Brasileira para Pesquisa da Potassa e do Fosfato, 1987. p. 12-48.

BROWN, R. H.; BLASER, R. E. Leaf area index in pasture growth. Herbage Abstracts, Farnham Royal, v. 38, n. 1, p. 1-9, 1968.

COMISSÃO DE FERTILIDADE DO SOLO DO ESTADO DE MINAS GERAIS. Recomendações para o uso de corretivos e fertilizantes em Minas Gerais: 5aa aproximação. Viçosa: EPAMIG/UFV, 1999. 359 p.

EVANS, G. C. The quantitative analysis of plant growth. Oxford: Blackwell Scientific, 1972. 734 p.

FAGUNDES, J. L.; SILVA, S. C.; PEDREIRA, C. G. S. Light interception and herbage accumulation in Tifton-85 swards grazed by sheep under continuous stocking. In: SIMPÓSIO INTERNACIONAL GRASSLAND ECOPHYSIOLOGY AND GRAZING ECOLOGY, 1999, Curitiba. Anais... Curitiba: UFPR, 1999. p. 339-343.

GARNIER, E. Growth analyses of congeneric annual and perennial grass species. Journal of Ecology, Oxford, v. 80, n. 5, p. 665-675, 1992.

GOMIDE, C. C. C. Algumas características fisiológicas e químicas de cinco cultivares de Cynodon. 1996. 100 f. Dissertação (Mestrado em Zootecnia) - Universidade Estadual Paulista, Jaboticabal, 1996.

GOMIDE, C. A. M.; GOMIDE, J. A. Morfogênese e análise de crescimento de cultivares de Panicum maximum. In: REUNIÃO ANUAL DA SOCIEDADE BRASILEIRA DE ZOOTECNIA, 33., 1996, Fortaleza. Anais... Fortaleza: SBZ, 1996. p. 403-405.

GOMIDE, C. A. M.; GOMIDE, J. A.; GRASSELLI, L. C. Aspectos fisiológicos da rebrota do capim-mombaça (Panicum maximum) sob quatro intensidades de desfolha. In: SIMPÓSIO INTERNACIONAL "GRASSLAND ECOPHYSIOLOGY AND GRAZING ECOLOGY”, 1999, Curitiba. Anais... Curitiba: UFPR, 1999. p. 333.

LOOMIS, R. S.; WILLIAMS, W. A. Productivity and the morphology of crop stands: pattern with leaves. In:
EASTIN, J. D. et al. (Eds.). Physiological aspects of crop yield. Madison: American Society of Agronomy, 1969. p. 27-47.

LUDLOW, M. M.; WILSON, G. L. Studies on the productivity of tropical pasture plants: II. growth analysis, photosynthesis, and respiration of 20 species of grasses and legumes in a controlled environment. Australian Journal of Agriculture Research, Victoria, v. 21, n. 2, p. 183-194, 1970.

OLIVEIRA, M. A.; PEREIRA, O. G.; GOMIDE, J. A. Análise de crescimento do capim-bermuda "Tifton 85" (Cynodon spp.). Revista da Sociedade Brasileira de Zootecnia, Viçosa, v. 29, n. 6, p. 1930-1938, 2000.

PARSONS, A. J.; JOHNSON, I. R.; HARVEY, A. Use of a model to optimize the interaction between frequency and severity of intermittent defoliation and to provide a fundamental comparison of the continuous and intermittent defoliation of grass. Grass and Forage Science, Oxford, v. 43, n. 1, p. 49-59, 1988.

PEDREIRA, C. G. S.; NUSSIO, L. G.; SILVA, S. C. Condições edafo-climáticas para produção de Cynodon spp. In: SIMPÓSIO SOBRE MANEJO DA PASTAGEM, 15., 1998, Piracicaba. Anais... Piracicaba: Fundação de Estudos Agrários “Luiz de Queiroz”, 1998. p. 85-114.

PINTO, J. C. Crescimento e desenvolvimento de Andropogon gayanus Kunth, Panicum maximum Jack. e Setaria anceps Stapf ex Massey cultivadas em vasos, sob diferentes doses de nitrogênio. 1993. $149 \mathrm{f}$. Tese (Doutorado em Zootecnia) - Universidade Federal de Viçosa, Viçosa, 1993.

RADFORD, P. J. Growth analysis formulae: their use and abuse. Crop Science, Madison, v. 7, n. 3, p. 171175, 1967.

WATSON, D. J.; WILSON, J. H.; FORD, M. A. Changes with age in the photosynthetic and respiratory components of the net assimilation rates of sugar beet and wheat. New Phytology, [S.l.], v. 65, n. 4, p. 500508, 1966.

WILSON, J. W. Analysis of growth, photosynthesis and light interception for single plants and stands. Annals of Botany, London, v. 48, n. 3, p. 507-512, 1981. 